\title{
Ventrally Located Cervical Dumbbell Ganglioneuroma Producing Spinal Cord Compression
}

\author{
Dong Wuk Son, Geun Sung Song, Young Ha Kim, Sang Weon Lee \\ Department of Neurosurgery, Pusan National University School of Medicine, Busan, Korea
}

Ganglioneuroma is an uncommon benign tumor and arise from neural crest cells or sympathetic and peripheral nerves. A 13-year-old boy was referred to our institute and presented with three-day history of right upper extremity weakness associated with neck pain for nearly one month. Magnetic resonance imaging showed right side dumbbell shaped extramedullary lesion at the C2-3 level extending outside through neural foramen. Paraspinal and posterior neck mass, cafe au lait spot was identified. We performed surgical decompression of the spinal cord by resection of intradural portion mass. Histopathological diagnosis was ganglioneuroma.

Key Words: Ganglioneuroma $\cdot$ Cervical spine $\cdot$ Neurofibromatosis

\section{INTRODUCTION}

Ganglioneuroma is the most mature form of neuroblastoma, originating from neural crest cells that normally migrate into the adrenal medulla and sympathetic ganglila. It can arise wherever sympathetic tissue exists and may be seen in the neck, posterior mediastinum, adrenal gland, retroperitoneum, and pelvis. The retroperitoneum and posterior mediastinum are the two most common locations for a ganglioneuroma, followed by the cervical region ${ }^{13)}$. Among the cervical gangnlioneuroma, only ten cases producing spinal cord compression have been reported in the English literature ${ }^{19)}$.

\section{CASE REPORT}

A 13-year-old boy was referred to our institute and presented with three-day history of right upper extremity weakness

\footnotetext{
- Received: September 5, 2013 - Revised: October 28, 2013

- Accepted: October 31, 2013

Corresponding Author: Geun Sung Song, MD, PhD

Department of Neurosurgery, Pusan National University Yangsan Hospital, 20,

Geumo-ro, Mulgeum-eup, Yangsan-si, Gyeongsangnam-do, Busan 626-770, Korea

Tel: +82-55-360-2126, Fax: +82-55-360-2156

E-mail: gnsong@pusan.ac.kr

"This work was supported for two years by Pusan National University Research Grant.

@This is an Open Access article distributed under the terms of the Creative Commons Attribution Non-Commercial License (http://creativecommons.org/ licenses/by-nc/3.0/) which permits unrestricted non-commercial use, distribution, and reproduction in any medium, provided the original work is properly cited.
}

associated with neck pain for nearly one month. Physical examination demonstrated several soft and movable subcutaneous masses on his posterior neck and we could identify several Cafe au lait spots on his trunk. There was no family history of neurofibromatosis. On neurologic examination, weakness of right elbow flexion (power, 4/5) and positive Spurling's sign at right side were present. There was no upper motor neuron sign, such as, hyperactive deep tendon reflex, ankle clonus, and Babinski sign. Cervical magnetic resonance imaging (MRI) showed right side extramedullary dumbbell shaped mass at the C2-3 level extending outside through neural foramen. The mass compressing spinal cord was isointense on T1-weighted image and showed slightly increased signal intensity on gadolinium-enhanced T1 weighted imaging (Fig. 1C, D). T1 and T2-weighted sagittal image revealed severely compressed spinal cord (Fig. 1A) and multiple masses at the pre-vertebral region and subcutaneous posterior neck area (Fig. 1B). The patient underwent surgical decompression of the spinal cord in a prone position through a posterior midline incision. Hemi-laminectomy of C2 was done without arthrodesis. The mass, which was significantly indenting the dura, was solid, elastic, less vascularized, and located purely extramedullary. We confirmed that the tumor mass was divided into foraminal and spinal canal portion, so, en block removal of spinal canal portion was available. Complete resection of foraminal canal portion of tumor without neural damage was impossible, because adhesions between the mass and dura were evident. Histopathology of the lesion (Fig. 2) was consistent with the diagnosis of ganglioneuroma. Postoperative MRI confirmed good decompression of the spinal cord and volume reduction of tumor(Fig. 3). His preoperative symptoms were 

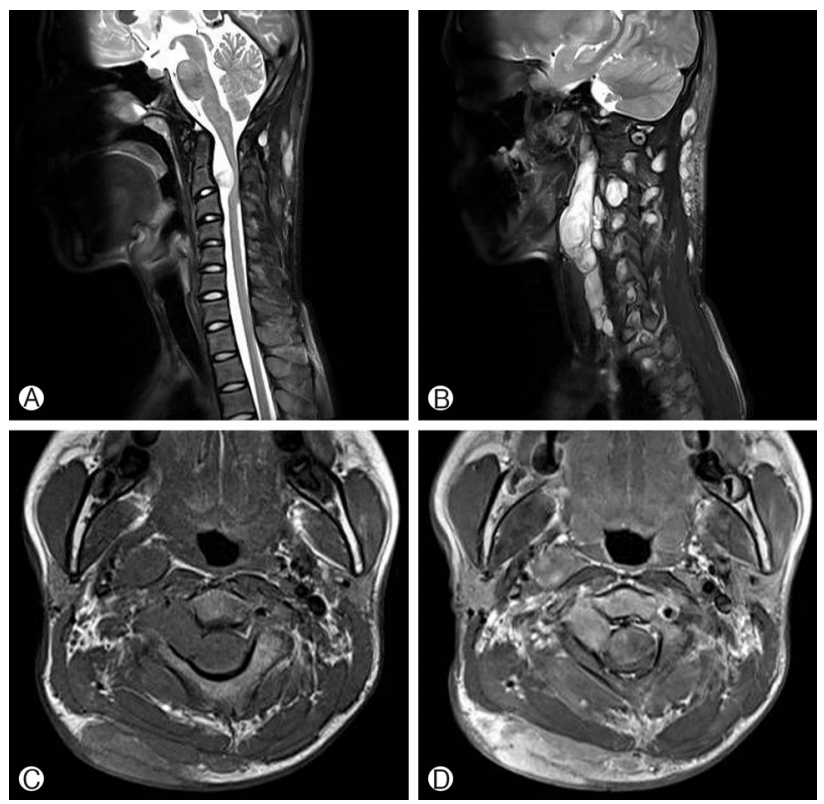

Fig. 1. Preoperative MRI of cervical spine: T1 (A) and T2-weighted (B) sagittal image showing severely compressed spinal cord and multiple masses at the pre-vertebral region (arrow) and subcutaneous posterior neck area (arrow head). Axial $\mathrm{Tl}$-weighted(C) and gadolinium-enhanced $\mathrm{Tl}$-weighted (D) magnetic resonance imaging (MRI) at the C2-C3 level showing a isointense dumbbell shaped mass with slight enhancement.

gradually relieved with no fresh neurological deficits after surgery. The postoperative course was uneventful and no additional therapy was administered.

\section{DISCUSSION}

Ganglioneuroma is rare, differentiated, benign, and slowgrowing tumor arising from the neural crest tissue of the sympathetic nervous system, and is histologically composed of mature Schwann cells and ganglion cells with fibrous stroma ${ }^{2)}$. Ganglioneuroma is most commonly located in the retroperitoneum and posterior mediastinum ${ }^{13)}$. A solitary ganglioneuroma at the cervicothoracic region arising from the cervical nerve root within the intervertebral foramen is extremely uncommon $^{11)}$. In some series, 0.8 to $3.5 \%$ of ganglioneuromas were dumbbell tumor ${ }^{9,16}$. Therefore, ganglioneuroma is seldom considered in the differential diagnosis of cervical dumbbell tumors. In 2011, Ji Zhang et al. ${ }^{19)}$ summarized previously published eleven cases of cervical ganglioneuroma producing spinal cord compression in the English literature, including their own case. A summary of these eleven cases and the present case showed that these lesions are mostly dumbbell shaped except one case and five of them were associated with neuro-

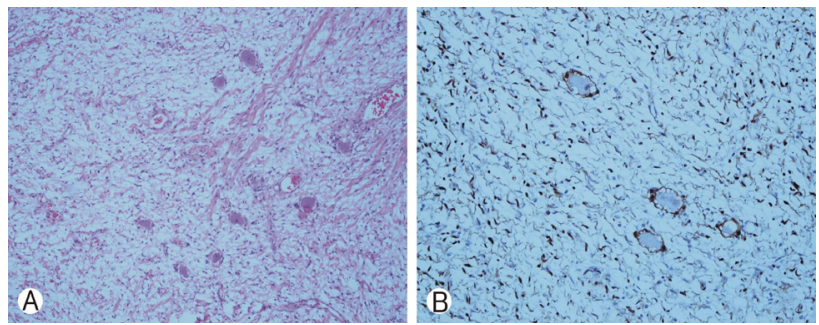

Fig. 2. (A) A microscopic view of the mass. The tumor was composed of large ganglion cells and wavy stroma containing spindleshaped cells, and did not show any evidence of malignant degeneration (Hematoxylin and Eosin staining, original magnification $\times 100$ ). (B) Immunohistochemical examination showed positive staining of ganglion and spindle cells for S-100 protein (original magnifi- cation $\times 200$ ).
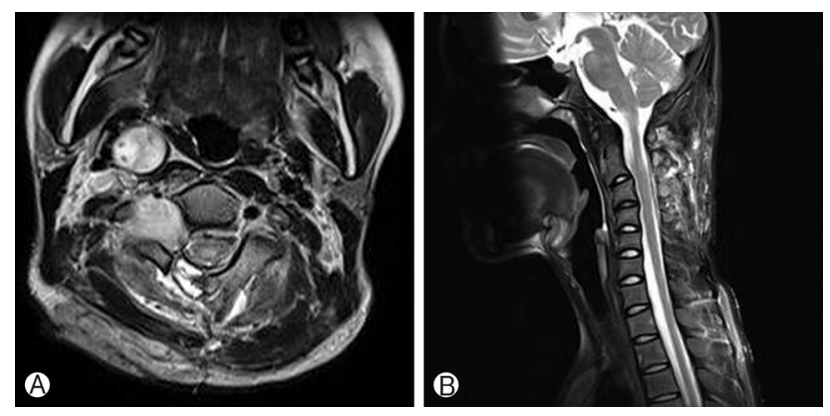

Fig. 3. Postoperative MRI of cervical spine: Axial T2-weighted imaging at the C2-C3 level (A) and sagittal T2-weighted imaging (B) showing good decompression of the spinal cord and volume reduction of tumor.

fibromatosis type 1 (NF-1). An association with NF-1 has been speculated in cases with multiple occurrences, but genetic associations between NF-1 and ganglioneuroma remain unclear, ${ }^{4,10)}$. Mean age was 32.96 years (range, 1.5-63 years). Gan- glioneuroma is generally considered to occur more frequently in children or young adults ${ }^{2,6}$. However, more recent studies have shown that the mean age at diagnosis of ganglioneuroma is around 40 to 50 years old $^{5,8,12,15)}$. Regarding treatment, surgical decompression should be undertaken as soon as possible when spinal cord compression is present as present case ${ }^{7}$. Ganglioneuromas are usually encapsulated masses with a firm consistency that complete surgical resection is the best option for solitary ganglioneuroma ${ }^{18}$. However, in cases of multiple tumor masses and tumors with the risk of damage to neural and vascular structure, it will be appropriate to do subtotal or partial removal of the lesion and relieve the spinal cord compression ${ }^{19)}$. Prognosis is generally favorable, considering that ganglioneuromas the most differentiated form of neuroblastic tumor have no metastatic potential. But local recurrence, regional lymph node metastasis, and malignant transforma- 
tion into malignant peripheral nerve sheath tumors have been reported $^{1,3,14,17)}$ therefore periodic radiologic surveillance should be performed after resection ${ }^{2}$.

\section{CONCLUSION}

Cervical dumbbell ganglioneuromas producing spinal cord compression are extremely rare and could be associated with NF-1. Complete surgical resection is the best option for solitary ganglioneuroma. However, decompression of spinal cord by using subtotal resection of tumor would be acceptable, if total resection is accompanied with risks of neural or vascular damage. We have presented an extremely rare case of NF-1 with dumbbell ganglioneuromas of the cervical spine.

\section{REFERENCES}

1. Garvin JH, Jr., Lack EE, Berenberg W, Frantz CN: Ganglioneuroma presenting with differentiated skeletal metastases. Report of a case. Cancer 54:357-360, 1984

2. Geoerger B, Hero B, Harms D, Grebe J, Scheidhauer K, Berthold F: Metabolic activity and clinical features of primary ganglioneuromas. Cancer 91:1905-1913, 2001

3. Jung HR, Kang KJ, Kwon JH, Kang YN: Adrenal ganglioneuroma with hepatic metastasis. J Korean Surg Soc 80:297-300, 2011

4. Kyoshima K, Sakai K, Kanaji M, Oikawa S, Kobayashi S, Sato $\mathrm{A}$, et al: Symmetric dumbbell ganglioneuromas of bilateral C2 and $\mathrm{C} 3$ roots with intradural extension associated with von Recklinghausen's disease: case report. Surg Neurol 61:468-473; discussion 473, 2004

5. Linos D, Tsirlis T, Kapralou A, Kiriakopoulos A, Tsakayannis D, Papaioannou D: Adrenal ganglioneuromas: incidentalomas with misleading clinical and imaging features. Surgery 149:99105, 2011

6. Lucas K, Gula MJ, Knisely AS, Virgi MA, Wollman M, Blatt $\mathrm{J}$ : Catecholamine metabolites in ganglioneuroma. Med Pediatr Oncol 22:240-243, 1994
7. Maggi G, Dorato P, Trischitta V, Varone A, Civetta F: Cervical dumbbell ganglioneuroma in an eighteen month old child. A case report. J Neurosurg Sci 39:257-260, 1995

8. Maweja S, Materne R, Detrembleur N, de Leval L, Defechereux $\mathrm{T}$, Meurisse $\mathrm{M}$, et al: Adrenal ganglioneuroma. A neoplasia to exclude in patients with adrenal incidentaloma. Acta Chir Belg 107:670-674, 2007

9. Miura Y, Okumichi T, Yoshioka K, Okumichi K, Kajihara H: Successful excision of a "dumb-bell" shaped ganglioneuroma of the posterior mediastinum with a large intraspinal component. Eur J Surg 159:635-638, 1993.

10. Miyakoshi N, Hongo M, Kasukawa Y, Misawa A, Shimada Y: Bilateral and symmetric C1-C2 dumbbell ganglioneuromas associated with neurofibromatosis type 1 causing severe spinal cord compression. Spine J 10:e11-15, 2010

11. Mullassery D, Dominici C, Jesudason EC, McDowell HP, Losty PD: Neuroblastoma: contemporary management. Arch Dis Child Educ Pract Ed 94:177-185, 2009

12. Qing Y, Bin X, Jian W, Li G, Linhui W, Bing L, et al: Adrenal ganglioneuromas: a 10-year experience in a Chinese population. Surgery 147:854-860, 2010

13. Rha SE, Byun JY, Jung SE, Chun HJ, Lee HG, Lee JM: Neurogenic tumors in the abdomen: tumor types and imaging characteristics. Radiographics 23:29-43, 2003

14. Ricci A, Jr., Parham DM, Woodruff JM, Callihan T, Green A, Erlandson RA: Malignant peripheral nerve sheath tumors arising from ganglioneuromas. Am J Surg Pathol 8:19-29, 1984

15. Rondeau G, Nolet S, Latour M, Braschi S, Gaboury L, Lacroix A, et al.: Clinical and biochemical features of seven adult adrenal ganglioneuromas. J Clin Endocrinol Metab 95:3118-3125, 2010

16. Shephard RH, Sutton D: Dumb-bell ganglioneuromata of the spine with a report of four cases. Br J Surg 45:305-317, 1958

17. Srinivasan R, Koliyadan KS, Krishnand G, Bhat SS: Retroperitoneal ganglioneuroma with lymphnode metastasis: a case report. Indian J Pathol Microbiol 50:32-35, 2007

18. Ugarriza LF, Cabezudo JM, Ramirez JM, Lorenzana LM, Porras LF: Bilateral and symmetric C1-C2 dumbbell ganglioneuromas producing severe spinal cord compression. Surg Neurol 55: 228-231, 2001

19. Zhang J, Li J, Shrestha R, Jiang S: Giant cervicothoracic ganglioneuroma. Neurol India 59:465-466, 2011 